\title{
nature
} cell biology

\section{Profit at a cost?}

The world of

biotechnology and

pharmaceuticals is a

wild place of high risk

and uncertain return. In

some cases, academic

laboratories have had to

retreat and sell off their

company interests when

faced with the

astronomical costs of

clinical trials
A lthough mere curiosity, love of discovery and altruism are sufficient motivations for most scientists to pursue research, a link to clinical applications is undoubtedly an advantage and sometimes even a requisite when it comes to funding. But how do basic research, clinical research and drug discovery benefit each other? Most biotechnology and pharmaceutical companies are well aware of the fact that the source of many future drugs is grounded in basic research, but few of them can actually afford to fund this research in the long run. Indeed, the actual productivity of a given scientific project is often unpredictable in terms of both how and when it will generate significant revenue. Scientists in small and medium-sized companies are often pressurized to produce results and requested to focus on rather short-term projects with a high likelihood of monetary reward. Such projects often involve the somewhat tedious improvement of previously discovered drugs rather than the more exciting screen for new drugs. This mentality, although understandable as a business principle, can drive some scientists back into academia for more freedom in their research.

As an alternative, other pragmatic scientists start up biotechnology companies or initiate collaborations with clinicians when their work seems to have possible exploitable applications, a course of action that is understandably gratifying both from a moral and from a financial point of view. But the world of biotechnology and pharmaceuticals is a wild place of high risk and uncertain return. In some cases, academic laboratories have had to retreat and sell off their company interests when faced with the astronomical costs of clinical trials. One example is SUGEN Inc. in southern San Franscisco, which aims to develop drugs by targeting the cell-signalling molecules that regulate protein phosphorylation. Last year its founders sold the company to Pharmacia Corporation (formerly Pharmacia \& Upjohn), stating that 'this agreement....provides SUGEN with the resources, critical mass and global infrastructure to commercialize the cancer drug candidate in our pipeline far more rapidly than [SUGEN] could achieve on [its] own'. Indeed, several anticancer drugs developed by SUGEN are currently in clinical trials, and one of the main reasons behind their acquisition by a larger company was the inability of SUGEN to afford the costs of phase III trials.

\section{Redirecting investment from basic research to genomics}

One would intuitively imagine that larger companies with an established and vast source of revenue would be more able to invest in long-term basic and clinical research ventures. But all too often the holder of the purse strings dictates the definition of long-term. Roche has financed the Basel Institute for Immunology (BII) for three decades. Its productivity in terms of science is unquestioned, with three Nobel prizes originating from research carried out there. In terms of revenue, however, the balance sheet for the BII is clearly in the red to Roche, which, faced with deteriorating communication between the company and scientists at the BII, has apparently now reached the limit of its generosity and decided to close the institute (see Nature 405, 605, 2000). Instead, Roche will develop a new medical genomics centre. This centre will be a department within the company rather than an independent institution, allowing scientists much less freedom and giving Roche much tighter control over the focus of their research than was the case at the BII. One wonders whether the decision was borne of economic necessity or of politics. Perhaps it reflects, more than anything, the growing emphasis on genomics in modern pharmaceutical research. 